\title{
Islam - Islamism - Islamist Terrorism? \\ A Proposal to Come to Terms with the Nexus of Islam and Security
}

Petra Weyland ${ }^{*}$

\begin{abstract}
... the conquest of the earth, which mostly means the taking it away from those who have a different complexion or slightly flatter noses than ourselves, is not a pretty thing when you look into it too much. What redeems it is the idea only. An idea at the back of it; not a sentimental pretence but an idea; and an unselfish belief in the idea - something you can set up and bow down before, and offer a sacrifice to.... ${ }^{1}$
\end{abstract}

After September 11, 2001, the West and its allies have responded to Islamist terrorism with the global war on terror. Since then, much success has been achieved, as many of Al-Qaeda's leaders have been killed or detained, and its structures and networks, as well as those of other terrorist organizations, have been destroyed. However, in spite of this multitude of efforts, no considerable victory over global Islamist terrorism has yet been achieved.

Many facts may be held accountable for this failure; it is the task of security experts to unearth the reasons for this, and to find ways to amend the deficiencies. Among these efforts should be the quest for an appropriate understanding of who the enemy is - in other words, the effort to depict an accurate image of the opponent. An inappropriate understanding of this opponent must necessarily have detrimental effects for achieving our aim, namely to achieve a higher level of security. An accurate image of the enemy is a crucial precondition for a victory of any kind, not only a military one. Yet it is exactly such an endeavor that is missing today. The image of the enemy in the global war on terror is not clearly defined, and it is inadequately thought through. It seems as if the concept of the image of the old enemy from the Cold War has simply been adapted to conceptualize the new enemies of the globalized, unipolar world, and as if the word "Soviet" has simply been replaced by the terms "Islamic" or "Islamist." Furthermore, this picture of our opponent is also too much inspired by a narrowly defined military perception for it to be a helpful tool for the fight against terrorism. The one-sidedness of this definition of course has to do with power. The necessary remedy therefore is to challenge the dominance of narrow-minded security experts in defining who the enemy is, and to bring to bear other perspectives, such as those of cultural experts and development specialists; even a female perspective is needed. Unfortu-

* Petra Weyland is a professor at the George C. Marshall European Center for Security Studies in Garmisch-Partenkirchen, Germany. The opinions expressed in this article are those of the author and do not necessarily reflect the policy of either the German or American governments.

1 Joseph Conrad, "Heart of Darkness," in Youth and Two Other Stories (Garden City, NY: Doubleday Page, 1925), 50-51. 
nately, all too often this demand is dismissed as irrelevant or even ridiculed by those who hold the power to define our enemies.

Even before September 11, terrorism was nearly always purposely or inadvertently equated with Islamic or Islamist terrorism. To be sure, this assessment has some plausibility, as many extremist Islamists themselves justify their attacks by making extensive reference to their religion. Yet taking these statements at face value does not help us much in understanding the nature of today's security threats. This is so because, contrary to what many Islamists - as well as Middle East and terrorism experts - want to make us believe, Islam, Islamism, and Islamist terrorism are extremely complex phenomena. If this complexity is not recognized and given the proper attention, the global community's struggle to counter terrorism will perhaps have the positive side effect of providing jobs and influential positions within the global security business establishment (as well as the "terrorism business"), but it will most probably have negative rather than positive consequences for its stated goal of ridding the world of the terrorist threat. The most dramatic result of this neglect would in fact be an increase rather than a decrease in the danger of Islamist terrorism.

This is, however, exactly what the world is facing today. As terrorism is ever more automatically and naturally treated as synonymous with Islamic terrorism, in the Muslim world the conviction is constantly gaining ground that the real aim of the global war on terror is not the defeat of terrorism, but that its hidden agenda is a war against Islam and against the entire Muslim world. It is of minor importance whether this assessment is empirically right or wrong. What is important is that a rising number of people in the Muslim world believe this analysis. The growing conviction that Islam is facing a death threat from an overwhelming military power has many serious repercussions. As a counter-reaction, Islamic identity is stressed all the more. This, of course, is not necessarily negative. But it becomes a serious issue when it is linked to an increasingly hostile anti-Western stance. An even more dramatic result is that a growing number of people express their understanding, appreciation, and respect for terrorists, even if they reject as un-Islamic the horrific methods they use. Terrorists find admiration because they are ready to sacrifice nothing less than their lives in the face of what more and more Muslims have come to perceive as a deadly threat to their religion.

Thus, the past few years have witnessed growing anxieties, negative prejudices, and mounting aggression towards the other from both sides, in the Muslim as well as in the Western world. In the West and the East, distrust, rejection, and defensive measures are increasing. Here as well as there, the culture of the other side is seen to be irreconcilable with one's own culture, and therefore to constitute a serious threat to one's own security. On both sides, the market in overly simplistic and demonizing images of the other are booming.

If it is our aim to achieve a higher degree of security and to avoid new conflicts, then it is of equally great importance for the West as well as for the Muslim world to prevent any further growth of these kind of negative stereotypes. As far as the West and its allies are concerned, we are in urgent need of a more appropriate way of dealing with the terms of Islam, Islamism, and terrorism, and - more generally - with the 
topic of Islam and security. The religion of Islam, like Christianity and Judaism, does not contain any inherent program of militancy. But, like other religions, Islam may also be instrumentalized in support of a higher level of (perceived) security or in response to a higher level of (perceived) threat. The reason is genuinely linked to the human species: Muslims are not different from any other human beings when they try to make sense of the world they are living in - they think and act; they struggle to understand their living conditions and their problems; they develop strategies to cope with their problems; and they struggle to achieve their aims.

What does this mean with regard to human beings living in the Muslim world? Without any doubt, over the past several decades, the living conditions of large segments of the population in the Middle East (and elsewhere in the Muslim world) have been constantly deteriorating. Many factors essential for development demonstrate this trend, such as participation in politics, self-determination, income, education, or health. What is important to understand is that the assessment of these societal problems and their repercussions on individuals - as well as the creation of counter-measures - takes place within the framework of one's identity, and very often of a particular ideology. Without a shared identity (and often ideology), no analysis is possible. Again, this is no peculiarity of Muslims, but one of human nature in general. As a matter of fact, until the late 1960s, the main source of identities and ideologies in the Arab-Muslim world for young nation-states, national liberation movements, and socio-revolutionary organizations alike - as well as for the masses - was the West. Liberalism, nationalism, racism, socialism, communism - all these concepts had been imported during the colonial period from the West with the aim of quickly achieving Western standards of development. As time went by, however, it became more and more obvious that in spite of all these concepts the gap between rich and poor, between powerful and powerless, was widening. While the living conditions of the societal elites improved, those of the masses deteriorated considerably. At the same time, the relative level of Western geostrategic, political, economic, and cultural domination rose sharply. These developments were accompanied by an expanding feeling in the Muslim world of severe injustice, and even humiliation. Given these developments, it is only too easy to understand that people turned to an alternative source of identity and ideology.

Given the failure of those Western ideologies and identities to fulfill the hopes and aspirations of the masses in the Muslim world, and given as well the association of Western identities with authoritarian regimes in the region, a new and viable alternative source of identity for the people could only be derived from authenticity, from their own culture. Could this possibly be anything other than Islam? Islamic identity became the rising star, and in this process the religion of Islam became ever more politicized. The aims which were to be reached through Islam are indeed very diverse: they range from an alternative moral code, a just political and economic system, and the observance of human rights, to the question of which contributions Muslim immigrants can make to European society, the quest for national independence (particularly for the Palestinians), and battles against an occupying power (Lebanon, Iraq), struggles against a corrupt regime (Egypt, Saudi Arabia), to the defense of the Muslim world 
against "the West" (Afghanistan, Iraq, young Muslim second generation immigrants in Western countries), to taking revenge in an eye-for-an-eye manner (Palestinian suicide bombings in Israel). Since approximately the end of the 1960s, the slogan "Islam huwa'l-hall" ("Islam is the solution") has become ever more popular with the Arab and Muslim masses. It almost has become the default identity and ideology of the developing world at the beginning of the twenty-first century. Islam is the keyword, yet what Islam is and how it should be defined remains very much in dispute. There is no single definition agreed upon or adhered to by all Muslims - there never was. Rather, here again the question of who has the power to impose a valid definition comes up. Definitions wrought by trained Islamic scholars very often differ fundamentally from those that political leaders (who are Muslim by creed but who never studied the tenets of this religion) have to offer on the market of ideologies. Thus, Islamist intellectuals and political activists often selectively pick and choose verses, translations, and ideas from the Qur'an to suit their own political and social purposes, and to legitimize with divine prescriptions their war against inequality and their other enemies, real or imagined.

Within the perspective developed above, it does not make much sense to see in Islamism or even Islam the main enemy. Islam - even Islamism - is not a security threat in its own right. Rather, Islam serves as a means to make sense of the world and to achieve legitimacy. In other words, this religion has been instrumentalized as a mobilizing ideology. From this perspective, Islam and Islamism can principally be exchanged with other sources of identity and ideology, just as Western, secular identities and ideologies were replaced by Islam (and ethnicity) in the second half of the last century. However, Islam can indeed serve as an extremely powerful source of identity because, as a religion, it not only provides divine answers to humankind's contingency problems, but it is also deeply rooted in the history of Arab societies. More than that, it has been very successfully constructed as the most important category of difference whenever one wants to epitomize the contrast between the "West" and the "Muslim" world. The big question then is, what comes next in terms of identity and ideology when Islamism and Islam have also proven their inability to solve the existential problems with which Muslim societies are confronted, a question that is becoming increasingly relevant in the Islamic Republic of Iran.

It is equally counterproductive to conduct the war against Islamist terrorism predominantly with military means. Again: today's enemy cannot be fought successfully with the recycled image of the enemy from the Cold War. The Islamist terrorist is not our deadly enemy the way a soldier of the Warsaw Pact had been the free world's enemy. Rather, terrorism has to be understood as a method and a strategy - as a tactic. And it is precisely the very atrocities of terrorist acts that betray the fundamental weakness of the enemy. Where one side is equipped with the latest technological innovations achieved by the revolution in military affairs, the other side has as its ultimate weapon the sacrifice of its own life.

There is a high likelihood that Islamist terrorism is a kind of extremist tip of the iceberg of an aggressive atmosphere, characterized by confrontational political positions and oppositional attitudes expanding broadly into large segments of society. If we 
understand extremism, including Islamic terrorism, as stemming from the center, and not the fringes, of a society, then Islamic terrorism could be understood as a kind of indicator for general tendencies within a society.

It goes without saying that terrorists have to be fought. If our aim is to achieve more security, however, then from a strategic point of view it is much more effective to focus on the general Muslim population - on their perspectives, needs, problems, and what they perceive as threats to the security of their lives - rather than concentrating exclusively on the terrorists. It is of paramount importance to thoroughly understand these issues, to take the people and their (Islamic) culture seriously, as well as to struggle to ameliorate extremely harsh living conditions whenever possible. By the same token, the West's dealings with the Muslim world must be judged by the people in this world to be fair and just. To the degree that this endeavor is successful, terrorists will no longer find support within the Arab and Muslim populations. Any prospective success of the Greater Middle East Initiative hinges on these principles.

If this alternative approach were to be given a chance, then we can also hope that today's fatal embrace between Islam and security may be dissolved. If the West would begin to take seriously the Arab-Islamic world's own concerns regarding security, and would promote the understanding of the fact that the security of both the West as well as the Muslim world are inextricably linked, and would act on this understanding, then the religion of Islam would probably have a greater chance to reveal its inherent potential to achieve more security for all in this one, globalized world. So, by way of conclusion, it is absolutely imperative for the West to understand the other side - in other words, to develop an emic perspective-if it wants to have a chance in winning its war against terrorism. 
THE QUARTERLY JOURNAL

\section{Bibliography}

Conrad, Joseph. "Heart of Darkness." In Youth and Two Other Stories. Garden City, NY: Doubleday Page, 1925. 